\title{
O reforço do "homem cordial" nas conexões entre senadores e cidadãos nas redes sociais online
}

\author{
[ The reinforcement of "cordial man" in the connections between \\ senators and citizens in online social networks
}

\section{Daniel Nardin Tavares ${ }^{\mathrm{I}}$}

\section{Tiago Quiroga²}

RESUMO - O presente artigo busca contribuir com as análises das chamadas redes sociais online a partir do viés cultural, especificamente o brasileiro. Com as novas tecnologias de comunicação, abriu-se a possibilidade de ser estabelecido o contato direto e rápido entre representantes e representados no Congresso Nacional, desde que sejam usuários de uma mesma plataforma de comunicação. Com base em levantamento junto às assessorias de comunicação dos senadores da $54^{\mathrm{a}}$ legislatura, verificamos que a substância cultural é um forte componente das trocas de mensagens presentes no aparato técnico propiciado pelo ambiente online, onde é marcante o reforço de traços do "homem cordial", de Sérgio Buarque de Holanda, cujas características parecem ser renovadas ou mesmo aprofundadas. PALAVRASCHAVE Senado Federal, redes sociais online, cordialidade. - ABSTRACT The aim of this paper is promote the analysis of the so-called social networks, in a Brazilian cultural point of view. With the development of the new Information and Communication Technologies, the possibility of a quick, direct contact among representatives and people at the Brazilian Congress was open. Through a data collection within the Senate's office of communication of the Senators from the 54th Legislature, it was found that the cultural component is the main subject of the online messages between the people and the representatives, which are remarkable the aspects of the Sérgio Buarque de Holanda's "cordial man", whose traces mean to be renewed or even gets deeper. - KEYwORDS Federal Senate, online social networks, cordiality.

Recebido em o9 de dezembro de $20 \mathrm{I} 3$

Aprovado em 25 de julho de 2014

TaVares, Daniel Nardin; Quiroga, Tiago. O reforço do "homem cordial" nas conexões entre senadores e cidadãos nas redes sociais online. Revista do Instituto de Estudos Brasileiros, Brasil, n. 6o, p. IIO-I28, abr. 2015 .

DoI: http://dx.doi.org/Io.II606/issn.23I6-90IX.voi6opIIo-I28

\footnotetext{
I Universidade de Brasília (UnB, Brasília, DF, Brasil).

2 Universidade de Brasília (UnB, Brasília, DF, Brasil).
} 


\section{INTRODUÇ̃̃o}

Na contemporaneidade, o processo comunicativo a partir de ferramentas técnicas que possam aumentar a disseminação e circulação de informação vem se tornando indispensável para o funcionamento e manutenção das democracias representativas. A imbricação da esfera política com a prática da comunicação é uma herança moderna, explicitada na esfera pública3. Tal íntima relação ganhou traços ainda mais marcantes com a emergência dos veículos de comunicação de massa, e, posteriormente, com a comunicação mediada por computador. No Brasil, além da imprensa tradicional, mercadológica e privada, coexistem como meio de divulgação do poder legislativo os veículos de comunicação institucional. Temos, nesse sentido, como exemplo o Senado Federal, que possui canal próprio de televisão, emissora de rádio, site, jornal e perfis institucionais nas chamadas redes sociais online. Esse processo de ampliação das formas de dar publicidade e visibilidade ao parlamento foi desenvolvido ao longo de décadas, ocorrendo paralelamente diversas iniciativas de comunicação por conta própria pelos senadores, de forma individual, numa comunicação mais personalista e que se diferencia da institucional adotada pelo Senado Federal.

Com o advento da internet, a comunicação personalista foi aprofundada pela possibilidade de segmentação do público, baixo custo para emissão de informações e de potencial garantia de espaço na esfera pública virtual. Se isto já ocorria através de endereços eletrônicos, com páginas pessoais de cada senador ou mensagens enviadas por $e$-mail para a caixa de entrada dos parlamentares, tal iniciativa foi ampliada de forma significativa com a maior popularização das redes sociais online, notadamente o Twitter e o Facebook. Os números de acesso à internet comprovam o crescimento desse espaço de comunicação e interação na sociedade. De acordo com levantamento disponibilizado pelo Instituto Brasileiro de Geografia e Estatística (IBGE), a Pesquisa Nacional por Amostra de Domicílios (Pnad) aponta que o número total de usuários teria chegado a 82,9 milhões em todo o Brasil4.

3 HABERMAS, Jurgen. Mudança Estrutural da Esfera Pública: Investigações Quanto a uma Categoria da Sociedade Burguesa. Rio de Janeiro, Tempo Brasileiro, 2003.

4 Pesquisa Nacional por Amostra de Domicílios. Indicadores 20II-20I2. Rio de Janeiro, IBGE, 20I3. Disponível em: 〈goo.gl/K7M4no〉. Acesso em: 4 abr. 2013. 
O ideal tecnicista privilegia uma abordagem que pretende fixar na sociedade a percepção de que a tecnologia é capaz de promover mudanças significativas no meio social, na cultura, inclusive do comportamento político. Segundo essa percepção, quanto mais a política puder ser classificada como interativa, online e se encontrar em um estágio técnico mais avançado, teríamos por consequência o pleno desenvolvimento também qualitativo das práticas políticas. Da mesma forma, quanto mais cidadãos, os representados, estiverem conectados de forma permanente com seus representantes, mais a política poderia configurar-se como transparente, observada e monitorada pela mobilização da população. Logo, tenderia também por apresentar-se mais ética, responsável e produtiva. Tudo isto, numa perspectiva idealista, seria decorrente da interatividade permanente propiciada com as novas tecnologias. As redes sociais, portanto, colocariam num mesmo plano de interação e diálogo os cidadãos e seus representantes, instrumentalizando mobilizações populares e, enfim, garantiriam a promoção de um poder legislativo mais plural e atento à pluralidade de vozes e discursos ${ }^{5}$ da sociedade.

A tecnologia, muitas vezes, pode pavimentar o caminho para que a população tenha os aparatos necessários a fim de acompanhar melhor os debates do campo político e, também, possa fiscalizar a destinação de recursos públicos ou mesmo organizar protestos em praças e avenidas fora do meio virtual para mostrar sua indignação. No entanto, esta é apenas uma das vertentes possíveis, uma vez que tais meios de comunicação técnicos são operados por pessoas. Logo, tais aparatos tendem reproduzir a forma com que a sociedade se relaciona com suas instituições. Assim, é necessário que se tenha clareza do amplo leque de variáveis de usos dessas tecnologias para evitar que palavras como interatividade sejam utilizadas sem a devida reflexão, carregando embutidos apriorismos que apontam uma relação direta entre o aperfeiçoamento da prática política pela questão técnica. Segundo Sérgio Buarque de Holanda ${ }^{6}$, o uso exacerbado de conceitos e teorias estrangeiras, forçando sua aplicação nas práticas sociais brasileiras, cria a falsa perspectiva de que programas, ideais e plataformas são suficientes para determinar a forma com que um povo lida com suas instituições públicas:

Foi essa crença, inspirada pelos ideais da Revolução Francesa, que presidiu toda a história das nações ibero-americanas desde que se fizeram independentes. Emancipando-se da tutela das metrópoles europeias, cuidaram elas em adotar, como base de suas cartas políticas, os princípios que se achavam então na ordem do dia. As palavras mágicas Liberdade, Igualdade e Fraternidade sofreram a interpretação que pareceu ajustar-se melhor aos nossos velhos padrões patriarcais e coloniais, e as mudanças que inspiraram foram antes de aparato do que de substância.?

\footnotetext{
5 CASTELLS, Manuel. Redes de Indignação e Esperança: Movimentos Sociais na Era da Internet. Rio de Janeiro, Zahar, 20I3.

6 HOLANDA, Sérgio Buarque de. Raízes do Brasil. 26. ed. São Paulo, Companhia das Letras, I995.

7 Idem, p. I79.
} 
Desta forma, pode-se compreender que o discurso tecnicista revela-se como uma atualização do discurso de cunho liberal e pode ser observado nas mais diversas justificativas de políticas públicas dos governos contemporâneos, conforme apontou Sodré: "Do fascínio centralizado na atividade da mídia e nas proezas da computação pode decorrer uma prática ideológica que atribui à inovação tecnológica em si mesma um poder mágico de solução dos problemas, independente das condições sociais e humanas”.

Assim, no diálogo agora possível e direto entre representantes e representados, o conteúdo de tal interação muitas vezes pode acabar reproduzindo práticas políticas já arraigadas na sociedade brasileira, especialmente quando adotamos a reflexão sobre a comunicação através das redes sociais online pela perspectiva cultural. Para Jesús Martin-Barbero", este percurso significa romper com a aparente segurança proporcionada pela redução da problemática da comunicação à das tecnologias.

Levando em consideração que a técnica de comunicação a partir da internet permitiu o contato direto e rápido, instantâneo, e ajudou a moldar uma esfera política que pode manter laços de interação e diálogo permanente com a sociedade, quebrando ou ao menos diminuindo barreiras, partimos para um olhar mais voltado ao conteúdo presente nesse tipo de prática comunicativa, entendendo que o viés tecnicista permite a visualização apenas da fachada e que cujo discurso ocasiona um perigoso deslumbramento. Desta forma, identificamos no funcionamento e intenção dos usos das redes sociais online por atores da esfera política alguns traços de uma substância não só presente, mas determinante no conteúdo da interação pretendida entre representantes e representados. Partindo desse viés de análise, recorremos a algumas argumentações trabalhadas por Sérgio Buarque de Holanda, ao destacar que nossa sociedade tem características personalistas enraizadas, priorizando o individual em detrimento do coletivo, permeando as ações na esfera pública de uma razão que leva em conta mais o emotivo que o racional, no que o autor adjetivou com o "homem cordial", afirmando que a cordialidade constitui a contribuição da sociedade brasileira à humanidade:

Em sociedade de origens tão nitidamente personalistas como a nossa, é compreensível que os simples vínculos de pessoa a pessoa, independentes e até exclusivos de qualquer tendência para a cooperação autêntica entre os indivíduos, tenham sido quase sempre os mais decisivos [...]. O peculiar da vida brasileira parece ter sido, por essa época, uma acentuação singularmente enérgica do afetivo, do irracional, do passional, e uma estagnação ou antes uma atrofia correspondente das qualidades ordenadoras,

8 SODRÉ, Muniz. Antropológica do Espelho: uma Teoria da Comunicação Linear e em Rede. Petrópolis, Vozes, 20II, p. IOI.

9 Para o autor, o estudo da comunicação esteve por muito tempo subordinado a certas disciplinas, como a psicologia e a cibernética. Para livrar-se dessa condição, acabou pagando um preço muito mais alto, que é o esvaziamento de sua especificidade histórica em troca de uma concepção radicalmente instrumental, na qual coloca-se que as transformações sociais e culturais são efeitos da mera implantação de inovações tecnológicas. MARTÍN-BARBERO, Jesús. Dos Meios às Mediações: Comunicação, Cultura e Hegemonia. Rio de Janeiro, UFRJ, 2009. 
disciplinadoras, racionalizadoras. Quer dizer, exatamente o contrário do que parece convir a uma população em vias de organizar-se politicamente. ${ }^{\text {to }}$

O conceito de cordialidade no pensamento buarquiano trata do aspecto cultural da personalidade brasileira, presente nas relações e vínculos da sociedade, sendo expressivo inclusive na intimidade, na religiosidade e mesmo nas questões mais públicas, como a orientação ou comportamento em assuntos políticos. Portanto, tendo a cordialidade como matriz cultural da sociedade brasileira, propomos que, trazendo ao nosso tempo, mesmo em ambientes estruturados tecnologicamente, poderiam então termos reforçadas velhas práticas da política brasileira, na forma como o cidadão brasileiro se relaciona com a "coisa" pública, priorizando o pessoal em detrimento do coletivo? Ou seja, a proximidade gerada pela técnica entre representante e representado, senador e cidadão, pode acabar proporcionando, também, um acirramento ou aprofundamento da recorrente confusão no imaginário nacional entre o que seria o limite do domínio público e do privado?

Para tal análise, recorremos a metodologias complementares no presente trabalho. Além de revisão bibliográfica sobre o processo histórico de desenvolvimento da comunicação legislativa no Senado Federal, também foi aplicado questionário junto às equipes de assessorias de comunicação de um terço (27) dos senadores da $54^{\mathrm{a}}$ Legislatura, sendo esta referente ao período de fevereiro de $201 \mathrm{II}$ a janeiro de $20 \mathrm{I} 5$. Para analisar as características da atual comunicação realizada pelos senadores, compreendemos ainda que é fundamental a adoção do método histórico ${ }^{\text {II }}$ como procedimento, uma vez que tal resgate é fundamental para pesquisar as raízes, compreender a natureza e função da vida social, das instituições e dos costumes que muitas vezes têm origem no passado. Por fim, a fase de coleta de dados foi combinada com observação etnográfica dos comportamentos e atividades de profissionais, servidores e dos próprios senadores durante os processos de comunicação. Para isso, durante todo o andamento da pesquisa, mantivemos conversas informais, registro de anotações e observações sobre as formas adotadas pelos parlamentares para a interação com cidadãos através das redes sociais online.

\section{A COMUNICAÇÃO LEGISLATIVA INSTITUCIONAL E PERSONALISTA NO SENADO FEDERAL}

O poder legislativo brasileiro remonta ao ano de I823, com a instalação e dissolução da primeira Constituinte. Mesmo há I9o anos, a comunicação tem sido um dos elementos com maior prioridade nas práticas políticas para que as decisões e discussões da esfera política obtivessem espaço na esfera pública. Para Jurgen Habermas, a passagem do modelo político baseado no absolutismo para o representativo, especialmente na Europa - com forte influência no Brasil - traz como uma de suas principais características a necessidade da experiência política

\footnotetext{
Io HOLANDA, Sérgio Buarque de, op. cit., p. 6I.

II LAKATOS, Eva Maria. Metodologia Científica. São Paulo, Atlas, 2004.
} 
ser também pública, ou seja, uma atividade que tem como condição para seu funcionamento a adesão do público. E, assim, a visibilidade gerada a partir da publicidade passa a desempenhar um papel central no campo político. No Brasil, essa passagem se dá na transição da condição de colônia da metrópole para a de país independente que, apesar de manter o regime monárquico, esboça a criação de mecanismos semelhantes, ao menos em fachada, aos sistemas políticos representativos de parte da Europa. Desta forma, no Senado do período Imperial e do início da República, a preocupação com a comunicação já era constante.

A Assembleia Geral passou a funcionar efetivamente a partir de I826, mesmo ano em que já era lançado o Diário da Câmara dos Deputados à Assembleia Legislativa do Brasil, que circulou por quatro anos e, segundo a pesquisadora Valéria Ribeiro Almeida $^{\mathrm{I2}}$, pode ser considerado o primeiro veículo de comunicação do legislativo brasileiro. A liberdade de imprensa, prevista na Constituição outorgada de I824, somava-se à adoção de instrumentos que permitissem ao parlamento expor suas atividades, como a publicação de diários oficiais com notas taquigráficas e resumos das sessões do parlamento. A medida era necessária por conta da acentuada falta de legitimidade da representatividade dos congressistas junto à sociedade. Já em I886, o senador Affonso Celso criticava ${ }^{\mathrm{T} 3}$ o modelo vigente na época, no qual "É um escárneo dizer-se que se rege pelo systema representativo uma nação de I3 a I4 milhões de habitantes que apenas conta com I50000 eleitores; impera a olygarchia!”.

O paradoxo da representatividade se dava tanto pela restrição de participação como na falta de identificação regional dos representantes dos estados no Senado, já que os senadores das províncias não residiam nos locais que representavam e, em alguns casos, pouco ou nenhum contato mantiveram com a realidade local ${ }^{\mathrm{I} 4}$. Desta forma, com o processo de fundação no Brasil das instituições que se pretendiam representativas é possível compreender o quanto a comunicação foi definida como meio para justamente tentar diminuir o abismo entre a vida cotidiana dos cidadãos e o parlamento brasileiro. Entre as estratégias estava, também nos moldes das democracias representativas de cunho liberal, a adoção da publicidade e do uso da imprensa. Assim, foram incrementadas iniciativas ao longo das décadas do último século que culminaram com a publicação de informativos e jornais com caráter institucional, assim como maior visibilidade dos trabalhos legislativos em veículos de comunicação privada. Inclusive, cabe ressaltar, é desse período a ainda recorrente prática de grupos políticos de investir em veículos de comunicação de massa, os quais possuem linhas editoriais intimamente ligadas aos projetos de poder político de seus proprietários ${ }^{15}$.

I2 ALMEIDA, Valéria Ribeiro da Silva Franklin. A Tecnologia na Comunicação do Senado: do Papiro à Internet. Dissertação de mestrado em Comunicação, Brasília, Universidade de Brasília, 2007.

I3 Pronunciamento registrado nos Anais do Senado do Império, em Ata de II de Junho de I886, p. III. Disponível em: 〈http://goo.gl/KiyWTN〉. Acesso em 2 ago. 2013.

I4 CERQUEIRA Leite, Beatriz Westin de. O Senado nos Anos Finais do Império (I870-I889). Brasília, Senado Federal, I978.

I5 HABERMAS, Jurgen. Political Communication in Media Society: Does Democracy Still Enjoy an Epistemic Dimension? The Impact of Normative Theory on Empirical Research. Philosophy Department, Johann-Wolfgang Goethe Universitat Frankfurt, Frankfurt, Germany, 2006. 
$\mathrm{Na}$ esfera da comunicação legislativa, a redemocratização na década de I980 e condições técnicas mais avançadas permitiram que fossem adotados mecanismos para ampliar a possibilidade de interação entre o Congresso Nacional e a sociedade. É relevante, neste sentido a década de I990, marcada pela inauguração de veículos de comunicação, especialmente rádio e televisão, como estratégia de divulgação do Senado Federal. A iniciativa foi possível após a aprovação da Lei n. 8977/1995, conhecida como Lei da Cabodifusão ${ }^{\mathrm{I}}$, que garantiu através de dispositivo legal a disponibilização de canais de utilização gratuita. A partir da década de I990, o Senado Federal passou a dispor de diferentes produtos de caráter jornalístico-institucional, como o Jornal do Senado, a Agência Senado, a Rádio Senado e a TV Senado, além de uma página eletrônica na internet. Com as novas ferramentas de comunicação, especialmente com a internet e as chamadas redes sociais de interação online, novas coordenadorias e serviços foram criados, com adaptações e mudanças ocorridas em diversas resoluções para a atual ${ }^{17}$ composição da estrutura em funcionamento da Secretaria Especial de Comunicação Social (SECS). Esta, que tem o objetivo prioritário de divulgar com tom mais próximo do jornalismo e da publicidade a instituição Senado Federal, é regida atualmente pelo Ato da Comissão Diretora n. $14 / 2013^{18}$, onde consta o Regulamento Orgânico do Senado Federal.

Como se trata de veículos de comunicação do poder público, notadamente mantidos com recursos e profissionais do serviço público, as ações da SECS enquadram-se nos princípios da administração pública, citados no art. 37 da Constituição Federal de I988: "A administração pública direta e indireta de qualquer dos Poderes da União, dos Estados, do Distrito Federal e dos Municípios obedecerá aos princípios de legalidade, impessoalidade, moralidade, publicidade e eficiência”. Desta forma, as regras desses canais oficiais de comunicação não permitem o favorecimento na divulgação do mandato de determinado parlamentar. Com isso, apesar da maior estrutura de comunicação institucional, manteve-se a necessidade dos senadores constituírem para si uma comunicação mais personalista, voltada para a divulgação do próprio mandato, com o objetivo de atingir a população do seu estado de origem. A Biblioteca do Senado Federal reúne boa parte desse tipo de produção, com cerca de I,8 mil arquivos impressos pela gráfica do Senado, com formatos que variam entre reprodução de pronunciamentos, resumo de notícias positivas publicadas na imprensa e publicações cada vez mais elaboradas e com conteúdo jornalístico próprio. É visível ainda o aumento não apenas na qualidade gráfica do material impresso, mas também do número de publicações desse tipo.

I6 Lei n. 8977/I995, que dispõe sobre o Serviço de TV a Cabo. Disponível em 〈http://goo.gl/aHOxN〉. Acesso em: 8 ago. 2013 .

I7 O organograma das coordenações, diretorias e chefias administrativas do Senado recebe significativas alterações a cada nova eleição da Mesa Diretora. Portanto, quando situamos a atual composição nos referimos ao período da coleta de dados, realizada em agosto de 2013.

I8 O ACD n. I4/20I3 foi publicado no Boletim Administrativo do Senado Federal n. 5233, Seção 2, em 29 de maio de 20I3. Disponível em: 〈http://goo.gl/qoWL4h〉. O Anexo II, que trata do Regulamento Orgânico do Senado Federal e traz o artigo 272, que aborda o funcionamento da SECS está disponível em: 〈goo.gl/pbC8To〉. Acesso em: 6 ago. 2012. 
Enquanto até a década de I980 foram encontradas aproximadamente 282 obras de cunho personalista dos senadores, esse tipo de publicação aumentou em cinco vezes nas três décadas seguintes, até 20Io, totalizando I428 impressos, conforme descrito na tabela I, a seguir.

\begin{tabular}{|c|c|}
\hline Década & Número de Publicações $^{20}$ \\
\hline I930-I939 & I \\
\hline I940-I949 & 0 \\
\hline I950-I959 & 3 \\
\hline I960-I969 & 27 \\
\hline I970-I979 & 25 I \\
\hline I980-I989 & 374 \\
\hline I990-I999 & 507 \\
\hline 2000-2009 & 547 \\
\hline 20I0-20I3 & 54 \\
\hline Total & I764 \\
\hline
\end{tabular}

Tabela I. Publicações dos Gabinetes de Senadores.

Ao longo dos últimos anos esse tipo de divulgação do mandato parlamentar não foi abandonado por conta de outras ferramentas disponíveis aos parlamentares com a Internet, mas sim, pelo contrário, foi aperfeiçoado, mostrando que as iniciativas se complementam. Desta forma, destacamos que a comunicação personalista não é uma novidade propiciada pela tecnologia, mas esta aprofundou esse tipo de prática e gerou mudanças significativas na relação entre senador e cidadão a partir da comunicação. De acordo com Recuero ${ }^{20}$, essas redes virtuais possuem como uma de suas características o espaço que permite o envio de mensagem a um único indivíduo de forma restrita e reservada:

Esses recursos são extremamente relevantes justamente por gerar um espaço seguro, ou seja, um espaço onde é possível desenvolver conversações que os atores envolvidos não estão dispostos a dividir com a rede social inteira. Essas conversações privadas também parecem ter relevância para a manutenção e o aprofundamento dos laços

I9 O levantamento foi feito junto à equipe técnica da Biblioteca do Senado Federal em Io de setembro de 20I3 e refere-se somente às publicações editadas pelo Senado Federal e que possuem material de divulgação da atividade parlamentar, produzida com apoio dos gabinetes dos senadores. Trata-se, portanto, de uma amostra encontrada no acervo da instituição, não representando assim sua totalidade.

20 RECUERO, Raquel. A Conversação em Rede: Comunicação Mediada pelo Computador e Redes Sociais na Internet. Porto Alegre, Sulina, 2012. 
sociais, uma vez que permitem ao ator focar em um grupo menor dentro de sua rede, estreitando ali componentes como a confiança e a intimidade. ${ }^{2 I}$

Confiança e intimidade, como sabemos, são sentimentos ou expressões típicas da cordialidade, isto é, de uma relação pessoal e que é permeada por diversos componentes, mas longe de qualquer conotação que remonte à impessoalidade que seria característica do poder público. Logo, o espaço privado numa rede social é, sobretudo, individualizado, pessoal, estreito e próximo. Ao menos é promovida essa expectativa entre seus usuários, especialmente por aqueles que tomam a iniciativa de iniciar um diálogo reservado no qual, então, o cidadão pode trocar mensagens de diferentes conotações e assuntos com seus representantes no Senado Federal. Desta forma, uma ferramenta tecnológica pode ser utilizada de diferentes maneiras, objetivos e estratégias. Tanto podem de fato moldar uma prática social mais libertária, democratizante e vigilante quanto aos temas de interesse coletivo da esfera política, como, pelo contrário, a conexão direta por essas redes pode ocasionar, também, o aprofundamento de uma prática que sugere maior intimidade e laços afetivos entre representantes e representados, cidadãos e suas instituições e o afrouxamento das hierarquias formais, características que são marcantes da cordialidade, um traço profundo da vida social brasileira, segundo Sérgio Buarque de Holanda.

É válido resgatar que o termo cordialidade recebeu pequenas - porém substanciais mudanças ao longo da formulação do conceito por Buarque de Holanda. O primeiro esboço para o que viria se constituir na obra Raízes do Brasil foi publicado na forma de ensaio, em I935, chamado "Corpo e Alma do Brasil: Ensaio de Psicologia Social", na revista Espelho, onde Holanda já imaginava a publicação de uma "Teoria da América”. De acordo com João Cézar de Castro Rocha ${ }^{22}$, no ensaio de I935, Buarque de Holanda afirmava que com a cordialidade e a bondade não se criam os bons princípios. A conjunção, desta forma, deixaria uma forte ligação entre cordialidade e bondade, algo que foi refutado pelo autor posteriormente:

Na primeira edição de Raízes do Brasil, no último capítulo, o leitor encontrava a mesma frase, porém com uma mudança decisiva, embora em aparência mínima: "Com a cordialidade, a bondade, não se criam os bons princípios”. Ora, não se trata mais de uma possível equivalência, mas de uma relação propriamente sinonímica: se não me equívoco na leitura que proponho, a substituição da conjunção aditiva pela vírgula estreita o vínculo semântico entre cordialidade e bondade. Na segunda edição de Raízes do Brasil, contudo, o reparo de Cassiano Ricardo deu frutos, pois agora a mesma passagem diz: "Com a simples cordialidade não se criam bons princípios”. Repito: não se altera o que vem imediatamente antes e depois da passagem citada, meramente se suprime a equivalência entre cordialidade e bondade, tornando a desavença de Cassiano Ricardo um simples despropósito. O leitor desavisado da terceira edição, portanto, ao ler o ensaio de Cassiano Ricardo e a carta-resposta de Sérgio Buarque

2I Idem, p. I5I.

22 ROCHA, João Cezar de Castro. Sergio Buarque de Holanda e Gilberto Freyre: Raízes de uma Rivalidade Literária. Dictae`Contradicta, n. 9. Rio de Janeiro, Civilização Brasileira; São Paulo, IFE, $20 I 2$. 
dificilmente compreenderá o ponto de vista do poeta. No entanto, a comparação das versões de Raízes do Brasil esclarece o claro enigma. ${ }^{23}$

Portanto, conforme o próprio Buarque de Holanda chegou a afirmar, a cordialidade significa uma ética de fundo emotivo, passional, que caracteriza a forma como o brasileiro se relaciona com a sociedade e suas instituições. A comunicação mediada por computador tem como uma das principais características a pretensa superação de barreiras físicas ou mesmo institucionais. A cordialidade, então, parece encontrar nesse novo ambiente - que sugere a superação do espaço pelo tempo e o afrouxamento das hierarquias - um terreno propício para se reproduzir ou mesmo ser aprofundada.

\section{A CORDIALIDADE NAS REDES SOCIAIS DOS SENADORES}

Nas redes sociais online pode ser observada a junção de ao menos duas funções da comunicação, a veiculação e a vinculaçã $0^{24}$, ou seja, as funções de promover e conquistar visibilidade na esfera pública e, também, formar laços afetivos mais próximos, permitindo a possibilidade de diálogo entre os usuários. Assim, nesse ambiente é possível ser efetivada uma comunicação que busca veicular as atividades da esfera política para a conquista de adesão e, paralelamente, a vinculação com grupos mais localizados e segmentados com abordagem de temas mais específicos, como associações de moradores, organizações não governamentais, sindicatos, entre outras ou mesmo com cidadãos individualmente. Nas redes sociais online, o espaço físico não é mais uma barreira, uma vez que as mensagens e diálogos podem ocorrer a qualquer momento. Em consequência, um cidadão não precisa se deslocar à sede física do poder para deixar uma mensagem ao seu representante. Isto já era possível com outras ferramentas - como exemplo o telefone e as cartas - mas a facilidade que a internet propiciou aumentou consideravelmente a prática de interação entre ambos.

Assim, a qualquer instante, o agente público pode ser abordado. E, nessa abordagem, diferentes interesses estão em jogo e determinam seu conteúdo, seja com questões coletivas de maior amplitude; temas de interesse direto para um grupo menor ou, ainda, solicitações de caráter estritamente privado. Para o presente estudo foram enviados ${ }^{25}$ questionários para as assessorias de comunicação dos 8I senadores da $54^{a}$ Legislatura. Coletamos com levantamento de campo (survey) 27 respostas,

23 Idem, p. 29.

24 SODRÉ, Muniz. op. cit., $20 I I$.

25 O questionário foi encaminhado por email, inclusive com mensagem anterior da Coordenação de Relações Públicas do Senado Federal, que tomou conhecimento da pesquisa em curso e pediu a colaboração dos servidores dos gabinetes. $O$ pedido de respostas ao questionário foi reforçado pessoalmente em visitas ao Senado e em ligações telefônicas aos gabinetes. O questionário recolheu respostas entre os dias I3 de setembro e I3 de novembro de 20I3, totalizando dois meses para fechar o resultado da amostragem, que reuniu 27 assessorias de senadores, um terço do universo total de parlamentares da casa parlamentar. $\mathrm{O}$ questionário está disponível em 〈http://goo.gl/AWvRaL〉. Acesso em: I4 nov. 2013. 
formando o grupo de um terço do total de senadores, fornecendo resultados representativos do universo pesquisado.

A primeira pergunta do questionário tratou das ferramentas de comunicação dos senadores no ambiente virtual. Verificamos que $88,9 \%$ possuem site pessoal, $37 \%$ blog, 8I,5\% perfil no Twitter, 85,2\% perfil no Facebook e 8I,5\% canal de vídeos no YouTube, conforme demonstra a tabela 2.

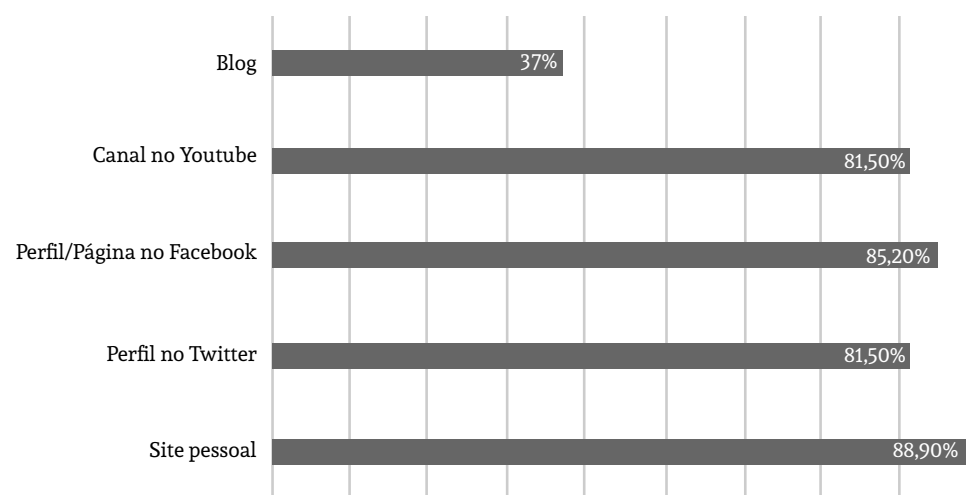

Tabela 2. Canais de comunicação online utilizados pelos senadores.

Cada uma dessas ferramentas possui uma linguagem própria. Nos sites pessoais ou nos canais no YouTube o formato é mais próximo do jornalismo, com registro de ações dos parlamentares e linguagem mais técnica. Já os perfis no Twitter e Facebook são marcados por uma linguagem mais coloquial, em sua maioria na primeira pessoa e que cria a expectativa de que é o próprio parlamentar, pessoalmente, que está emitindo as mensagens. Porém, apesar dessa característica, verificamos que muitas das vezes esta é, na verdade, uma estratégia adotada pela equipe de comunicação do parlamentar para que a linguagem esteja adaptada ao ambiente, voltada especialmente para criar uma proximidade maior com o público leitor. Os resultados da segunda pergunta encaminhada às assessorias de comunicação confirmam essa leitura, uma vez que o resultado coletado mostra que os senadores fazem a manutenção dos perfis nessas redes sociais com o auxílio ou acompanhamento, em diferentes níveis, de suas assessorias de comunicação. Em nenhuma resposta verificamos que exclusivamente é o senador que atualiza esses canais de comunicação nas redes sociais. Assim, conforme demonstra a tabela $3,44,4 \%$ informaram que a responsabilidade de responder e atualizar o perfil é compartilhada, com maior participação da assessoria. Já o grupo com $22,2 \%$ dos entrevistados informou que os profissionais de comunicação do gabinete parlamentar são os responsáveis pela manutenção das páginas. Outro item, "ambos em conjunto, com maior participação do senador", foi a opção escolhida por I4,8\% dos entrevistados. E, em II,I\% dos casos, a definição é híbrida, com o Twitter sendo atualizado pelo próprio parlamentar e o Facebook pela assessoria. 


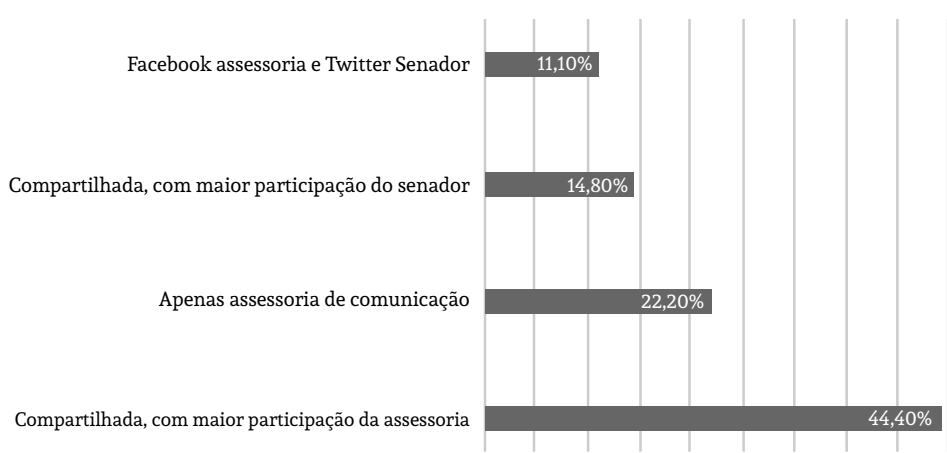

Tabela 3. Responsabilidade por manutenção dos perfis nas redes sociais online.

A tabela 3 confirma que a inserção de perfis nas redes sociais online é acompanhada de perto por uma equipe de profissionais. Desta forma, alguns aspectos culturais da sociedade foram carregados para esse novo ambiente interativo não por obra do acaso ou capricho e sim por uma questão estratégica. À luz do pensamento buarquiano podemos então analisar o quanto a cultura influenciou e ainda influencia a linguagem e a dinâmica adotada na comunicação entre senadores e cidadãos nas redes sociais de interação online. A postura essencialmente personalista, a proximidade gerada pela técnica e a linguagem coloquial, longe de qualquer formalidade, promove a possibilidade da amizade, um terreno fértil, portanto, para a prática da cordialidade em ambientes onde seria marcante justamente o oposto, ou seja, a impessoalidade.

Uma das características que compõem a formação das redes sociais na internet está relacionada à qualidade dos laços sociais presentes e sua construção ${ }^{26}$. Assim, se o cidadão quisesse apenas obter informações sobre o mandato de um parlamentar, buscaria o site pessoal ou outros mecanismos para obter reportagens e matérias a respeito. Na dinâmica da rede social online, porém, a intenção em tese deve ser dialogar e não apenas divulgar. Logo, a pessoa gramatical geralmente adotada pelos parlamentares - primeira pessoa do singular - busca justamente atender algumas características desse ambiente de conversação online, como o diálogo direto sem a participação de terceiros ou intermediários, a interação próxima e mesmo certa intimidade com o interlocutor.

Assim, o diferencial proposto pelas redes sociais é justamente permitir a expectativa aos cidadãos de que o parlamentar está presente no espaço e aberto às cobranças e ao diálogo. Além da questão da dinâmica e gramática própria do Twitter e do Facebook, temos na postura ao adotar uma linguagem pessoal, a presença de uma das características da cultura política brasileira, marcada justamente pelo personalismo. Ao criar um perfil e dialogar com os cidadãos, inclusive abordando assuntos fora dos temas políticos, o parlamentar favorece a geração de sentimentos que sejam mais próximos do carisma, do emocional e do afetivo. Como afirmou Sérgio Buarque de Holanda, nosso comportamento não reconhece por muito tempo a dureza das instituições e, assim, o

26 AMARAL, Adriana; FRAGOSO, Suely; RECUERO, Raquel. Métodos de Pesquisa para Internet. Porto Alegre, Sulina, 2012. 
rigorismo do rito se afrouxa e humaniza. Boa parte destes cidadãos quer mais do que ler o que o parlamentar escreve e divulga. Desejam conversar, ser amigo, estar numa conexão mais próxima, mais forte e, quando possível, mais exclusiva. Ou seja, a ideia é receber a informação mas, se for possível, estreitar essa relação e diminuir os abismos hierárquicos que a separam, uma vez que os obstáculos geográficos, físicos e institucionais já podem ser superados pela técnica. Esse desejo de intimidade com autoridades e a falta de rigor com as instituições é um dos temas centrais da cordialidade buarquiana:

Nosso temperamento admite fórmulas de reverência e até de bom grado, mas quase somente enquanto não suprimiam de todo a possibilidade de convívio mais familiar. A manifestação normal do respeito em outros povos tem aqui sua réplica, em regra geral, no desejo de estabelecer intimidade. ${ }^{27}$

Então, neste laço social gerado pela comunicação mediada por computador, emerge uma relação mais individual e profundamente personalista. A cordialidade se apresenta, portanto, logo na "fachada" e o conteúdo das mensagens trocadas revela ainda mais a possibilidade ou estratégia de gerar intimidade entre representantes e representados. Aprofundando a questão da interatividade pelas redes sociais, levantamos a seguinte pergunta: “O perfil segue outros usuários do Twitter?”. O questionamento colocando apenas o Twitter é pertinente, uma vez que, ao contrário dessa rede social, a plataforma do Facebook não exige que um perfil siga o outro para que possa ser enviada uma mensagem direta reservada. $O$ espaço das mensagens reservadas, destaque-se, constitui-se no ambiente propício para que a cordialidade se revele ainda mais por permitir maior intimidade e um diálogo mais restrito. Assim, 58,3\% informaram que o parlamentar segue de volta outros usuários, que o mesmo recebe as mensagens privadas, mas responde apenas algumas. Já 33,3\% dizem que seguem outros usuários e que recebem e respondem a todas as mensagens. Outro grupo ( $8,3 \%$ ) respondeu que não segue outros perfis de usuários, como ilustra abaixo a tabela 4. As respostas ajudam a evidenciar as diferenças e, sobretudo, a preocupação dos perfis de senadores em seguir outros usuários, ou seja, tentar estabelecer laços de conexão mais fortes. Mas, os dados mostram também que nem todos os usuários tem a possibilidade de enviar ou mesmo ter sua mensagem respondida pelo parlamentar.

Sim. recebe as mensagens, mas responde apenas algumas

Sim. recebe as mensagens privadas e responde todas

Não

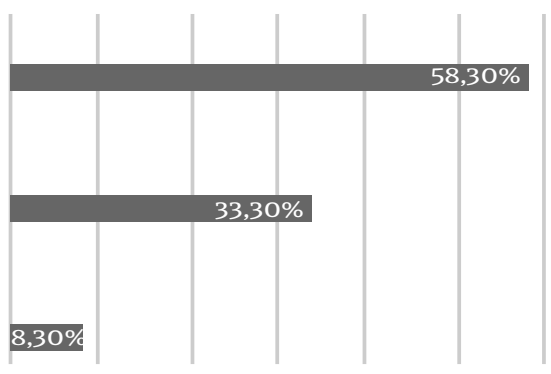

Tabela 4. O perfil no Twitter segue outros usuários. Se sim, quanto às mensagens privadas recebidas.

27 HOLANDA, Sérgio Buarque de, op. cit., p. I47. 
Também procuramos conhecer o teor dessas mensagens enviadas pelas redes sociais online. Os entrevistados poderiam responder em mais de um item de escolha e, assim, verificamos que quase todos marcaram as três opções sugeridas. O item "Manifestações sobre projetos de lei, votações em andamento e outras atividades afins exclusivamente do mandato no Senado Federal" recebeu 9I\% das respostas e as outras duas opções, seguintes "Manifestações sobre o posicionamento partidário do parlamentar" e "Manifestações com solicitações e pedidos de cunho mais pessoal" receberam o mesmo número de respostas (87,5\%). Portanto, de acordo com o levantamento, as redes sociais online abrigam tanto as manifestações com mensagens de teor coletivo como aquelas que são enviadas com o objetivo de ganho pessoal, conforme apresenta a tabela 5 .

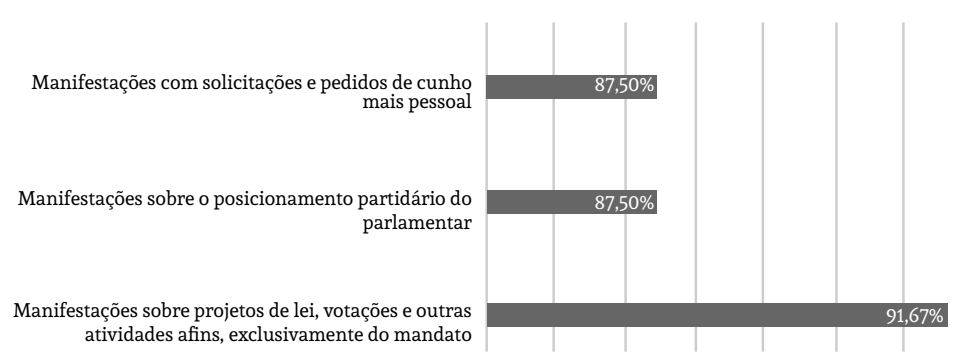

Tabela 5. Sobre o conteúdo das mensagens enviadas por cidadãos via redes sociais online.

Conforme revela a tabela 5 , nestes espaços ocorrem manifestações de cunho coletivo e mobilizações de grupos de pressão em favor de projetos de lei. No entanto, nesse mesmo espaço podemos ter a sobreposição da ética de fundo emocional sobre a ética racional, que deveria ser característica das ações desenvolvidas no âmbito da burocracia política e do legislativo. O comportamento cordial, segundo o pensamento buarquiano, resulta num tipo de convívio que busca estabelecer intimidade e superação de distâncias socialmente construídas, especialmente em ambientes mais formais, impessoais e típicos da burocracia estatal e da gestão administrativa pública. Com as novas tecnologias de comunicação, ocorreu a superação das distâncias físicas e a facilidade de contato mais próximo entre agentes públicos e cidadãos, num patamar antes praticamente impossível ou quando efetivo era circunstancial. $\mathrm{O}$ ambiente virtual tornou-se um terreno fértil para que a cordialidade brasileira fosse novamente reforçada, onde tal particularidade cultural foi carregada com vigor para o ambiente online, não só pela questão técnica, mas especialmente pela linguagem e discurso adotado pelos senadores ao se fazerem presentes nesse novo ambiente interativo.

Esse tipo de postura e relacionamento com a esfera política pela sociedade parece ter se enraizado, uma vez que foi historicamente construída. Ou seja, trata-se de conduta e procedimento que acabaram sendo incorporados entre as diversas expressões do jeito cordial de ser do brasileiro. Portanto, mesmo que não seja ofertada a possibilidade de ganho pessoal por um vínculo técnico e virtual com os senadores pelas redes sociais online, é comum que cidadãos encaminhem seus pedidos a eles. Isto decorre, aliás, por inúmeros fatores, especialmente por conta de um sistema de 
serviços públicos deficiente e por uma questão cultural, com as constantes quebras de formalidades e afrouxamento das regras no interior das instituições. O conteúdo dessas mensagens enviadas por cidadãos pelas redes sociais online e relatada por senadores na pesquisa de campo, são expressas condutas que apresentam aquela nossa forma de convívio tão típica que se efetiva justamente como o oposto da polidez, o nosso horror às distâncias e uma atitude onde o rigorismo do rito se afrouxa e se humaniza ${ }^{28}$. Uma forma de convívio ditada por uma ética de fundo emocional e onde nenhuma elaboração política seria possível senão fora dela, fora de um culto que só apela para os sentimentos e os sentidos, quase nunca para a razão.

Ou seja, como sentenciou o autor, o peculiar da vida brasileira é justamente a acentuação de aspectos mais afetivos e passionais em detrimento das qualidades ordenadoras, racionalizadoras e próximas do ideal de impessoalidade e razão que caracterizam as burocracias e o ideal de administração pública segundo o modelo ocidental. Nas palavras de Buarque de Holanda, "exatamente o contrário do que parece convir a uma população em vias de organizar-se politicamente"29.

Lembramos que, no canal de diálogo direto com o cidadão pelas redes sociais online, as mensagens trocadas nessas redes podem ocorrer basicamente de duas formas: pública ou privada. A pública é aquela que pode ser vista por outros usuários além dos interlocutores diretamente envolvidos. Porém, tanto no Twitter como no Facebook temos os espaços mais reservados, onde a troca de mensagens não pode ser vista por terceiros. De acordo com Raquel Recuero: "Essas conversações privadas também parecem ter relevância para a manutenção e o aprofundamento dos laços sociais, uma vez que permitem ao ator focar em um grupo menor dentro de sua rede, estreitando ali componentes como a confiança e a intimidade" ${ }^{\circ}$. Confiança e intimidade são sentimentos ou práticas típicas da cordialidade, isto é, de uma relação pessoal e que é permeada por diversos componentes, mas longe de qualquer conceito de impessoalidade. Logo, o espaço privado numa rede social é, sobretudo, individualizado, pessoal, estreito e próximo. Ao menos cria-se essa expectativa em um dos seus usuários, especialmente por aquele que inicia o diálogo reservado num desses esconderijos da virtualidade. Justamente por ser este um espaço cujo acesso não é permitido a terceiros que buscamos relatos dos senadores sobre o conteúdo das mensagens recebidas dos cidadãos diretamente e de forma mais privada. Afinal, esse ambiente é um dos criados nas redes sociais online e que reforça ou enfraquece os vínculos criados a partir do espaço público da internet.

De acordo com parlamentares ouvidos na pesquisa de campo, verificamos solicitações que sugerem a possibilidade da clássica troca de favores - pedidos de empréstimo financeiro, tratamento de saúde, eletrodomésticos, presentes - e que cuja prática, própria do clientelismo, parece se renovar nesse ambiente virtual, uma vez que, como colocou Sérgio Buarque de Holanda, é possível acompanhar ao longo de nossa história o predomínio constante das vontades particulares e uma gestão pública onde a ordenação impessoal tem pouco acesso. Lembramos, contudo, que

28 Idem, p. I47.

29 Idem, p. 6I.

30 RECUERO, Raquel, op. cit., p. I5I. 
muitas vezes essa "troca" não é ofertada pelo parlamentar nesse espaço virtual. Pelo contrário: ele divulga em sua rede sua atuação, seus votos nas sessões ou ações realizadas no âmbito legislativo. Mas, ainda assim, são comuns e constantes os pedidos pessoais partindo dos indivíduos. Isso decorre, portanto, de uma vinculação entre cidadão e autoridade marcada historicamente por uma formação cordial, de uma ética de fundo emocional e não de ordem racionalizadora. E, também, em boa medida por práticas políticas extraoficiais que ainda são comumente exercidas em todos os cantos do país.

\section{CONSIDERAÇÕES FINAIS}

A comunicação por iniciativa dos próprios senadores dos trabalhos legislativos esteve na ordem do dia em diferentes períodos do parlamento brasileiro e a preocupação em adotar uma linguagem e dinâmica personalista é significativa, muito por conta do próprio sistema político ser representativo e o senador dependente do consentimento da população para a conquista de votos, que fazem a manutenção do seu poder político. Com as atuais novas tecnologias e as redes sociais online, tivemos um aprofundamento dessa lógica, marcada pela proliferação de sites pessoais e perfis dos senadores nessas redes que tem, sobretudo, a característica de promover a interação direta entre representantes e representados.

Assim, é perceptível a influência da cultura norteando as práticas e vínculos gerados por meios técnicos, mesmo quando isso se desenvolve em espaços que se pretendem ser impessoais e formais como as instituições do sistema político. A personalização da comunicação dos senadores ocorre tanto no fato de que temos não apenas o site do Senado Federal na internet, mas sim dezenas de endereços eletrônicos e perfis nas redes sociais online de cada senador divulgando suas ações, buscando dialogar com a sociedade - preferencialmente cidadãos de seu estado de origem - e adotando uma postura que busque aproximar o cidadão de maneira mais direta, próxima e cordial possível.

A escolha por uma linguagem em primeira pessoa, mesmo quando efetivamente não é o parlamentar que está ali e sim sua representação, evidencia a influência da cultura nas ferramentas e espaços institucionais. Tanto o tom adotado como em boa medida os assuntos abordados - muitas vezes os senadores atualizam seus perfis com assuntos pessoais, como comentários esportivos, encontros com amigos ou familiares, participação em eventos, entre outros - revelam uma perspectiva e expectativa de contato mais próximo, mais personalista.

Pela própria dinâmica de relacionamentos nas redes sociais online temos a expectativa de promover amizade, ainda que virtual, entre seus usuários. Se tal vínculo é formado entre um senador e um cidadão, são superados obstáculos institucionais e geográficos. Desta forma, temas coletivos, partidários, angústias e necessidades pessoais são recorrentes e parelhos nas manifestações dos cidadãos, como foi visto no levantamento realizado. Isso se dá tanto pela cultura do brasileiro ao lidar com as instituições e seus representantes como pela dinâmica característica presente com as novas tecnologias de comunicação. É significativo notar que 
nessas novas redes sociais a interação direta ocorre em maior amplitude do que nas estratégias de comunicação adotadas anteriormente e ainda em curso pelas assessorias dos senadores, uma vez que jornais, informativos ou outras iniciativas não permitiam com tanta facilidade a resposta ou indagação direta e permanente dos cidadãos junto aos seus representantes.

Nas redes sociais online temos um movimento difuso: tanto a inclinação para mobilização e participação política em temas de interesse coletivo como, pelo contrário, a interatividade pode também promover justamente o oposto e acirrar ou aprofundar a expectativa de troca de favores, a conquista de projetos pessoais e o atendimento de solicitações de cunho estritamente individual. E isso se dá, sobretudo, pela cultura da cordialidade brasileira que desconhece ou afrouxa as instituições e hierarquias, uma substância que independe do aparato em que tal vínculo é operado e que ganha novos contornos justamente no ambiente online, onde a proximidade entre usuários isolados é uma de suas principais características.

Afinal, a cultura cordial brasileira revela-se na crença de que o cidadão ao ter maior proximidade com o poder público, com o contato certo, a pessoa certa e na hora certa, pode buscar atingir ou ao menos revelar as expectativas de ganhos individuais, em detrimento ou não de questões de cunho coletivo, que podem ocorrer paralelamente. Assim, na amostragem que obtivemos, verificamos que ao mesmo tempo que são apresentados pelos cidadãos questionamentos sobre a atuação parlamentar, temos também solicitações e pedidos de cunho pessoal. Antes que esse fato seja classificado como uma perversão ou empobrecimento do "objetivo" das redes sociais online, é preciso compreender que as redes são apenas plataformas ou aparatos para onde, afinal, são levados a substância, a cultura e o comportamento do brasileiro em relação às suas instituições.

Ainda sobre o resultado do vínculo direto entre representante e representado podemos observar a possibilidade de um enfraquecimento cada vez maior de organizações coletivas locais, como associações, clubes, agremiações e partidos políticos. Antes das redes sociais online as reivindicações sobre a situação de uma rua, de um posto de saúde ou da escola do bairro eram geralmente feitas através desses grupos, que então procuravam seus representantes no poder público para tratar de assuntos coletivos ou através da imprensa tradicional, que se ainda se porta como defensora ou portadora da opinião pública.

Hoje, no entanto, um cidadão não necessita cumprir essas etapas nos campos midiáticos e políticos tradicionais para dialogar e cobrar seu representante. Pelo contrário, pode fazer isso de forma direta, rápida, com um clique. E então, quanto mais conectados, podemos estar cada vez menos reunidos em associações coletivas com objetivos comuns. Ao tempo que a tecnologia pode permitir maior acompanhamento da gestão pública e o tratamento de questões coletivas, temos certo prejuízo ou queda de prestígio de associações e contatos mais próximos entre membros de uma mesma comunidade pelas associações, partidos ou outros mecanismos modernos de representação. Paralelamente, temos as tecnologias atuando no reforço do nosso comportamento cordial frente nossas instituições e autoridades, priorizando ainda mais as demandas individuais e pessoais em detrimento das coletivas e impessoais. Ou seja, a cordialidade se adapta e utiliza as tecnologias para se reforçar. A estrutura 
técnica para um molde estrangeiro de democracia representativa moderna estaria recebendo então um novo enxerto pelo viés cultural brasileiro.

Conforme colocou Sérgio Buarque de Holanda no último parágrafo de Raízes do Brasil, ao afirmar que poderemos ensaiar a organização de nossa desordem segundo esquemas sábios e de virtude provada, mas há de restar um mundo de essências mais íntimas. E estas permanecerão sempre irredutíveis e desdenhosas das invenções humanas. Para que essas questões sejam devidamente tratadas é preciso afastar o "demônio pérfido e pretensioso que se ocupa em obscurecer aos nossos olhos essas verdades singelas", conforme ponderou Sérgio Buarque de Holanda ${ }^{3 \mathrm{I}}$, no encerramento de Raízes do Brasil, apontando uma visão sem apriorismos ou preconceitos, deixando claro que a nossa cultura cordial tende a adaptar e criar novas perspectivas diante dos moldes modernos e externos.

A identificação da particularidade do caso brasileiro da presença da cordialidade em campos que segundo os modelos modernos racionais estariam distantes do emocional, do afetivo e do cultural apresenta estes e outros questionamentos fundamentais para análise, reflexão e compreensão das atuais dinâmicas sociais e das práticas e condutas políticas adotadas e possíveis a partir das novas tecnologias de comunicação. Como colocou Buarque de Holanda, podemos ensaiar a organização de nossa desordem segundo esquemas sábios e de virtude provada. Podemos utilizar a técnica como ferramenta para aprimorar nossos modelos. Porém, deve-se ter a consciência de que tal receita não é outra senão aquela que possui em sua essência um caldo cultural com os traços marcantes, como não poderia deixar de ser, de nossas raízes, das raízes do Brasil.

\section{SOBRE OS AUTORES}

DANIEL NARDIN TAVARES mestre em Comunicação e Sociedade pela Faculdade de Comunicação da Universidade de Brasília (UnB) em 20I4, linha de pesquisa Teorias e Tecnologias da Comunicação. Bacharel em Comunicação Social, com habilitação em Jornalismo, pela Universidade Federal do Pará (UFPA) em 2007. E-mail: nardin.daniel@gmail.com

TIAGO QUIROGA doutor em Ciências da Comunicação pela Escola de Comunicações e Artes da Universidade de São Paulo (ECA-USP) e mestre em Comunicação e Cultura, pela Escola de Comunicação da Universidade Federal do Rio de Janeiro. Membro permanente do Programa de Pós-Graduação em Comunicação da UnB. E-mail: tagori@terra.com.br

3I HOLANDA, Sérgio Buarque de, op. cit, p. I88. 


\section{REFERÊNCIAS BIBLIOGRÁFICAS}

ACD n. I4, de 20I3. Boletim Administrativo do Senado Federal, n. 5233, Seção II, 29 maio 20I3. Disponível em: 〈http://goo.gl/qoWL4h〉. Acesso em: 6 ago. 2012.

ALMEIDA, Valéria Ribeiro da Silva Franklin. A Tecnologia na Comunicação do Senado: do Papiro à Internet. Dissertação de mestrado em Comunicação, Brasília, Universidade de Brasília, 2007.

AMARAL, Adriana; Fragoso, Suely; \& Recuero, Raquel. Métodos de Pesquisa para Internet. Porto Alegre, Sulina, 2012.

BRASIL. Lei n. 8977, de 6 de janeiro de I995. Dispõe sobre o Serviço de TV a Cabo e dá outras providências. Disponível em <http://goo.gl/aHOxN〉. Acesso em: 8 ago. 2013.

CASTELLS, Manuel. Redes de Indignação e Esperança: Movimentos Sociais na Era da Internet. Rio de Janeiro, Zahar, 2013.

CERQUEIRA Leite, Beatriz Westin de. O Senado nos Anos Finais do Império (I870-I889). Brasília, Senado Federal, I978.

HABERMAS, Jurgen. Mudança Estrutural da Esfera Pública: Investigações Quanto a uma Categoria da Sociedade Burguesa. Rio de Janeiro, Tempo Brasileiro, 2003. .Political Communication in Media Society: Does Democracy Still Enjoy an Epistemic Dimension? The Impact of Normative Theory on Empirical Research. Philosophy Department, Johann-Wolfgang Goethe Universitat Frankfurt, Frankfurt, Germany, 2006.

HOLANDA, Sérgio Buarque de. Raízes do Brasil. 26. ed. São Paulo, Companhia das Letras, I995.

IBGE. Pesquisa Nacional por Amostra de Domicílios. Indicadores 20II-20I2. Rio de Janeiro, IBGE, 20I3. Disponível em: 〈goo.gl/K7M4no〉. Acesso em: 4 abr. 2013.

LAKATOS, Eva Maria. Metodologia Científica. São Paulo, Atlas, 2004.

MARTÍN-BARBERO, Jesús. Dos Meios às Mediações: Comunicação, Cultura e Hegemonia. Rio de Janeiro, UFRJ, 2009.

RECUERO, Raquel. A Conversação em Rede: Comunicação Mediada pelo Computador e Redes Sociais na Internet. Porto Alegre, Sulina, 2012.

ROCHA, João Cezar de Castro. Sergio Buarque de Holanda e Gilberto Freyre: Raízes de uma Rivalidade Literária. DictaeContradicta, n. 9. Rio de Janeiro, Civilização Brasileira; São Paulo, IFE, 20I2.

SANT’ANNA, Francisco. Mídia das Fontes: um Novo Ator no Cenário Jornalístico Brasileiro - um Olhar sobre a Ação Midiática do Senado Federal. Brasília, Senado Federal, 2009.

SODRÉ, Muniz. Antropológica do Espelho: uma Teoria da Comunicação Linear e em Rede. Petrópolis, Vozes, 20II.

WEBER, Max. Ensaios de sociologia. Rio de Janeiro, LTC, 2010. 